\title{
DESIGN OF WIND TURBINE SYSTEM INTEGRATED WITH BATTERY ENERGY STORAGE SYSTEM
}

\author{
${ }^{1}$ Güngör BAL, ${ }^{2}$ Süleyman Emre EYİMAYA \\ ${ }^{1}$ Department of EEE, Faculty of Technology, Gazi University, Ankara-Turkey \\ Email: gunbal@gazi.edu.tr \\ ${ }^{2}$ TUSAŞ Scholl of Vocation, Gazi University, Ankara-Turkey \\ Email: eyimaya@gazi.edu.tr
}

\begin{abstract}
Due to uncontrolled natural variables such as wind speed, the correlation between the renewable energy production and the demand is strenuous. In order to make the renewable enrgy system effective the energy storage systems are utilized employing the, control systems for the enegy in the battery and power. In addition, the rapidly changing wind speed, particularly in wind turbines, causes variations in the power obtained from wind causing instability at a higher power levels. The system engaged in storing energy is employed to reduce fluctuations in power and to maintain stability of power systems. In this study, a wind turbine system integrated with energy storage system was created. This system is modeled and tested in MATLAB / Simulink. The results obtained evinces that the proposed system reduces power fluctuations and succeeds in meeting load demand
\end{abstract}

Keywords: Renewable energy systems; Wind turbines; power fluctuations; power system stability, Battery energy storage systems.

\section{INTRODUCTION}

Global warming, fossil fuel depletion, craving for energy independence an ever-increasing demand for power has heightened the curiosity and research on energy that are renewable in recent years [1]. Among renewable energy sources, wind energy stands out with its advantages that can be provided in any season, day or night $[2,3]$.

Wind energy remains as the befitting solution in the area where the installation of the conveyance system are costly. In small-networks applied in such areas, the sources of the in exhaustible power follows the demand in the load power to avoid fluctuations in the voltage and frequency. As the speed of the wind is a natural phenomenon and hard to be controlled, it becomes difficult to follow the demands in the load., so this paves way for the utilization of the small networks, photovoltaic systems, wind system, energy storage cells 
Journal of Electrical Engineering and Automation (EEA) (2019)

Vol.01/ No. 02

Pages: $72-82$

https://www.irojournals.com/iroeea

DOI: https://doi.org/10.36548/jeea.2019.2.002

and the diesel generators in a hybrid manner to supply the energy as per the demand[4]. Various studies have been made on wind turbine and energy storage hybrid systems. "Energy storage technologies are key components in these systems. Different energy storage technologies such as chamber pump storage systems, compressed air storage systems, batteries, flow cells, hydrogen-based storage systems, superconducting magnetic energy storage systems, flywheels and supercapacitors reduce power fluctuations, increase voltage and frequency stability and power quality of the power system and can be used for various purposes according to peak reduction properties" [5].

The problem combining the inexhaustible enrgy source and the power gird necessitates the need for energy storage systems [6]. Energy storage systems are utilized to serve the demands of the energy loads, /offer regulation in frequency and voltage. However, in power surge reduction applications, batteries, superconducting magnetic energy storage systems, supercapacitors, and flywheels are widely utilized due to their fast response and long life characteristics [7].

Static, compact and modular structure, easy to install, low maintenance cost, highly efficient, and quick response Reducing power fluctuations in hybrid renewable energy systems and energy storage applications that are grid-scale, [8]. Though various BESS schemes are researched, Li-On batteries have become the subject of further research with the fast charge-discharge characteristics, along with the quick response and great cycle life.

Many renewable systems have been modeled by research on various alternative energies [9-10]. Many other studies [11-13] involving modeling of hybrid sources have been included in the literature. Several studies have been proposed to achieve the required power ripple reduction with reduced BESS capacity [14-16]. Two time-scale coordination control of the storage system to reduce wind energy fluctuations [17], a double-layer control strategy involving surge reduction control [18] and the energy storage system sizing method [12] for wind energy integration, by combining BESS with the supercapacitor In storage technologies, reducing energy storage capacity and extending the life of BESS [19] are examples of these studies.

In this study, a wind farm system with battery energy storage system is designed to increase the quality of the power transmitted to the grid. However, it focuses on reducing power fluctuation and performing energy management by determining reference power values. It is used as Li-On based BESS system for energy storage. The performance of the system is verified by simulation studies. 
Journal of Electrical Engineering and Automation (EEA) (2019)

Vol.01/ No. 02

Pages: $72-82$

https://www.irojournals.com/iroeea

DOI: https://doi.org/10.36548/jeea.2019.2.002

\section{Battery energy storage systems (BESS)}

Energy storage is emerging as a requirement for energy quality and sustainability in renewable energy sources. Storage devices are often used to protect sensitive electronic devices from power quality problems. Unless the frequency and voltage fluctuations often seen in electrical power systems are eliminated, the system becomes completely unstable and insecure. The fast response and stability required for system stability can be met by the energy storage system. Energy storage systems can provide robust, long-lasting and cost-effective power savings for long-term wind turbine applications. What's more, energy storage systems provide emergency and backup power to improve reliability. Load tracking, additional power capacity, energy and frequency support, improving power quality, reducing power fluctuations in the power system, BESS's contributions to the power system.

Unlike conventional energy sources, the most significant disadvantage of renewable sources is that they cannot be stored for later use. Therefore, despite their limited availability, the need to obtain maximum energy from these sources is crucial. Moreover, since the energies used tend to depend on climate conditions, it is difficult to ensure that they are consistent and stable. This makes renewable energy sources very erratic and unstable. Because of the extreme unpredictable behavior of the wind, the power generated by the wind turbine is very susceptible to harmonic distortions and related faults that could damage the operation of the system. In such cases energy storage systems are needed to eliminate irregularities and improve power quality. BESS is required to control power outputs and is an indispensable source of energy to ensure maximum efficiency from renewable energy systems [16].

BESS is required to reduce power fluctuations in wind turbines and solar panels. BESS stores excess energy when the output power of the wind turbine and solar panels is higher than the energy demand. Stored energy is used when energy production is not sufficient. This requires an effective BESS. Recent advances in energy storage technologies provide an opportunity to increase the use of renewable energy and reduce fluctuations in output power [20-31].

\section{Proposed wind turbine system and energy storage system}

The proposed scheme comprises the wind turbine and storage system for the energy. The created system is designed in Matlab / Simulink. The Figure.1 is the block diagram of the proffered; wind turbine, permanent 
Journal of Electrical Engineering and Automation (EEA) (2019)

Vol.01/ No. 02

Pages: $72-82$

https://www.irojournals.com/iroeea

DOI: https://doi.org/10.36548/jeea.2019.2.002

magnet synchronous generator (PMSG), rectifier, inverter, Li-On based battery energy storage system (BESS), load (or network) along with the energy managing control system.

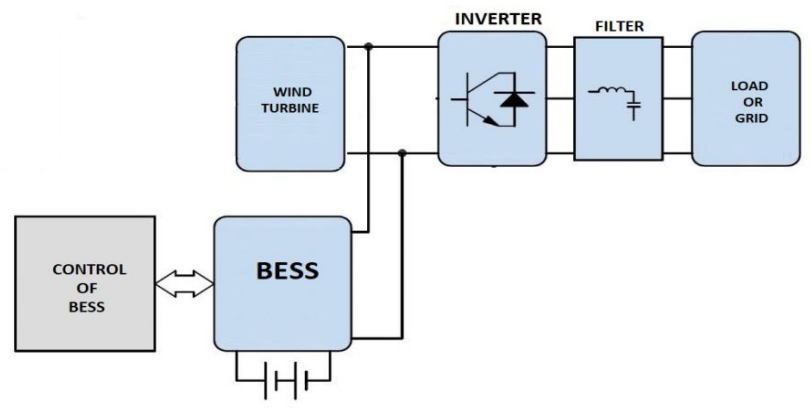

Figure 1. System with Wind Turbine and BESS

\subsection{Wind turbine system model}

The wind-power system model whose parameters are given in Figure 2 consists of a $8.5 \mathrm{~kW}$ three-phase protruding synchronous generator enabled with the permanent magnet (PMSG), wind turbine and wind anglecontrol system.

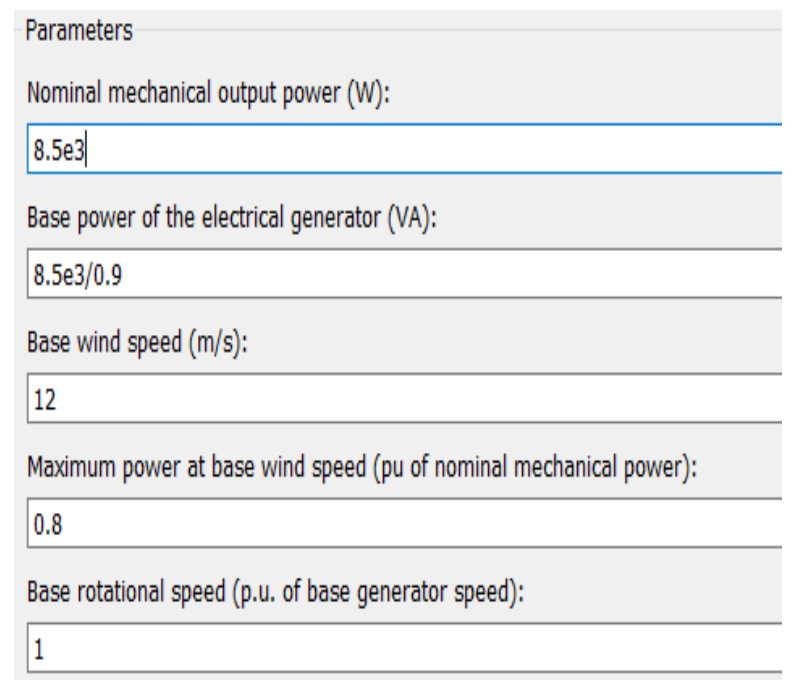

Figure 2. Parameters in Matlab / Simulink model of wind turbine block 
Journal of Electrical Engineering and Automation (EEA) (2019)

Vol.01/ No. 02

Pages: $72-82$

https://www.irojournals.com/iroeea

DOI: https://doi.org/10.36548/jeea.2019.2.002

In the wind turbine, PMSG produces three-phase alternating current with the kinetic energy generated by the rotation of the blades with the wind. Wind speed determines the voltage as well as the frequency. As can be seen in Figure 3, the continuously changing wind speed is defined in the system. These values are set to change at specific time intervals. The generated energy must be converted into a constant frequency, constant voltage AC power. Therefore, the output voltage of the PMSG must be corrected. In addition to the rectifier circuit, MPPT is used to ensure extreme conversion efficiency of the energy. The torque reference utilizing the wind speed variable is determined using the MPPT algorithm. The torque reference generated is obtained by using the rectified wind speed and DC voltage acts as the references for current. The hysteresis controller is utilized in generating the switch signal for the MPPT. Wind turbine Matlab / Simulink model is given in Figure 4.

\begin{tabular}{|c|}
\hline $\begin{array}{l}\text { Parameters } \\
\text { Time (s): }\end{array}$ \\
\hline$\left[\begin{array}{llll}0.5 & 1.5 & 2.5 & 4.5\end{array}\right]$ \\
\hline Amplitude: \\
\hline$\left[\begin{array}{lllll}5 & 12 & 8 & 12 & 8\end{array}\right]$ \\
\hline
\end{tabular}

Figure 3. Wind speed variations in time

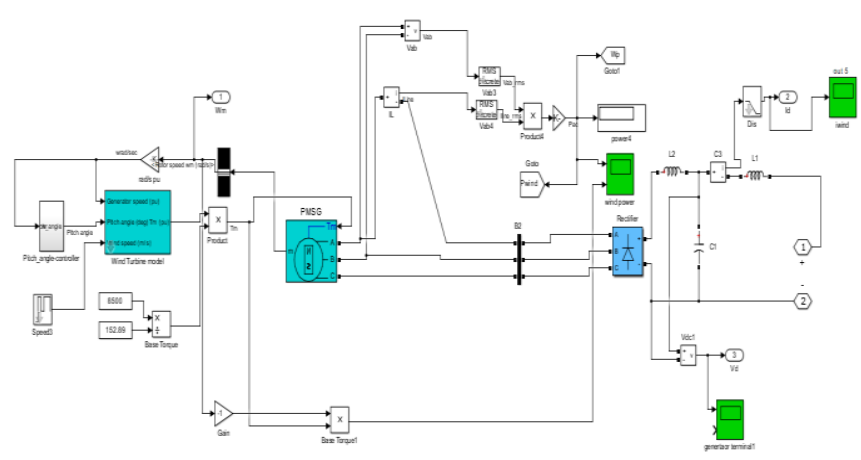

Figure 4. Matlab / Simulink model of wind turbine 
Journal of Electrical Engineering and Automation (EEA) (2019)

Vol.01/ No. 02

Pages: $72-82$

https://www.irojournals.com/iroeea

DOI: https://doi.org/10.36548/jeea.2019.2.002

\subsection{Model of battery energy storage system}

BESS is connected to the DA bus via the bi-directional DA-DA converter this compensates as well as minimizes the power fluctuations in the output obtained in the energy conversion system engaged for wind. The $150 \mathrm{~V}, 6.5 \mathrm{Ah} \mathrm{Li-On} \mathrm{battery} \mathrm{in} \mathrm{the} \mathrm{system} \mathrm{is} \mathrm{framed} \mathrm{as} \mathrm{in} \mathrm{Figure} 5$.

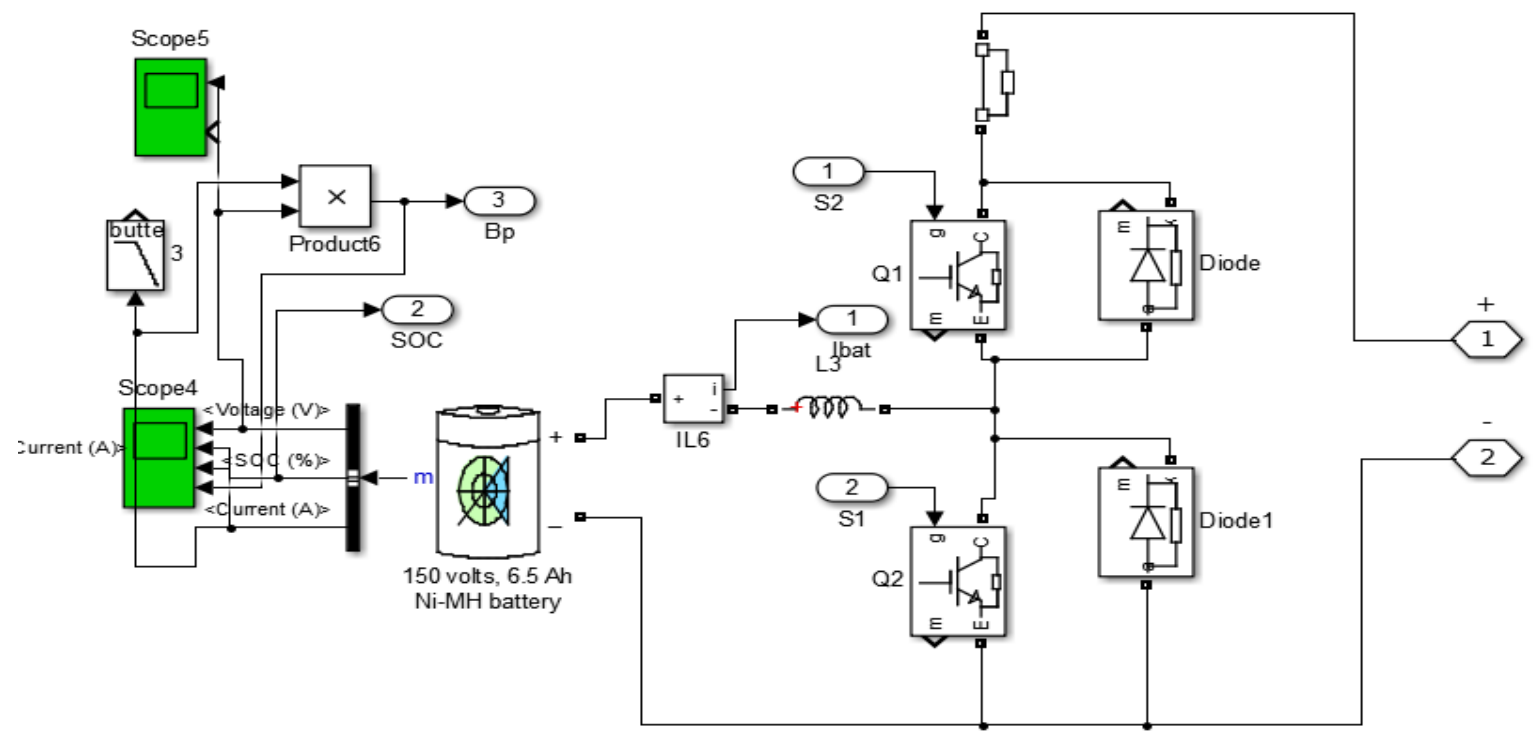

Figure 5. Matlab / Simulink model of BESS

Within the modeled hybrid system, time varying wind speed data is entered into the system. A $150 \mathrm{~V}$, 6.5 $\mathrm{Ah} \mathrm{Li-On} \mathrm{battery} \mathrm{is} \mathrm{included} \mathrm{in} \mathrm{the} \mathrm{system} \mathrm{to} \mathrm{compensate} \mathrm{for} \mathrm{the} \mathrm{energy} \mathrm{of} \mathrm{fluctuating} \mathrm{renewable} \mathrm{sources.}$ This energy storage system controls battery, wind turbine and load. With this control, it is aimed not to transfer the fluctuations in the wind turbine to the load. 
Journal of Electrical Engineering and Automation (EEA) (2019)

Vol.01/ No. 02

Pages: $72-82$

https://www.irojournals.com/iroeea

DOI: https://doi.org/10.36548/jeea.2019.2.002

\subsection{Simulation results}

The obtained power from the wind turbine based on the simulation is shown in Figure 6. Since the wind speed input having a continuously changing structure in the modeled system is processed into the system, it is seen that the wind turbine has a continuously changing structure as a result of simulation with the change of wind speed. This undulating power structure adversely affects the power quality. It is seen that the output power is directly proportional to the speed of the wind.

Parameters
Time (s):
$\left.\begin{array}{llll}\hline 0.5 & 1.5 & 2.5 & 4.5\end{array}\right]$
Amplitude:
$\left[\begin{array}{lllll}5 & 12 & 8 & 12 & 8\end{array}\right]$


Journal of Electrical Engineering and Automation (EEA) (2019)

Vol.01/ No. 02

Pages: $72-82$

https://www.irojournals.com/iroeea

DOI: https://doi.org/10.36548/jeea.2019.2.002

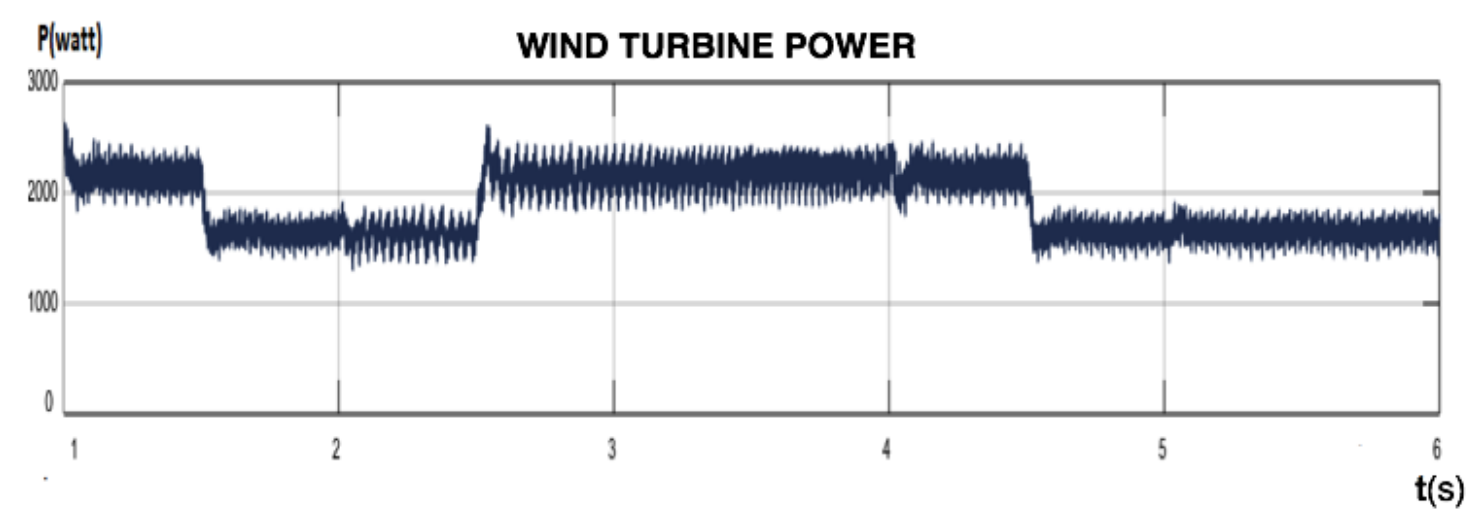

Figure 6. Wind turbine system output power graph

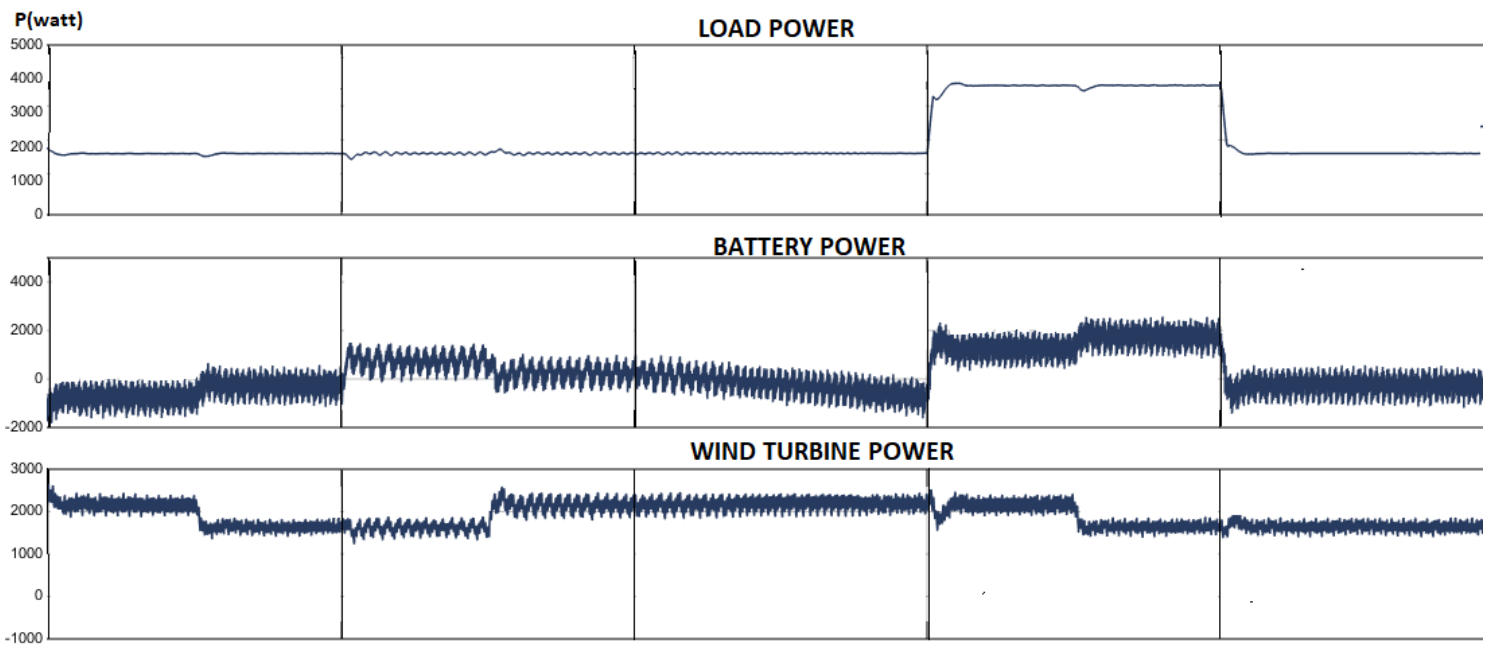

Figure 7. Variation of powers in the modeled system

Figure 7 shows the changes in all power values in the system, the wind turbine output power obtained by the variable values of the wind speed, integrated into the power obtained as a charge or discharge battery power to the load at required times and load power varies depending on demand. It is seen that wind turbine power fluctuations decrease in the power graph transferred to the load at the system output and the system becomes more stable. However, in case of reductions in wind turbine output power, the battery power is activated and the required load power is met. It is seen that the system works efficiently and reduces fluctuations in the time period when the load increases. When the wind turbine cannot meet the energy demand, the energy system is supported by the battery providing the amount of energy to meet the demand in the load. Thus, the battery is discharged and the charge level decreases.

ISSN: 2582-3051 
Journal of Electrical Engineering and Automation (EEA) (2019)

Vol.01/ No. 02

Pages: $72-82$

https://www.irojournals.com/iroeea

DOI: https://doi.org/10.36548/jeea.2019.2.002

Wind energy could be low or high when compared to the power demand based on the speed of the wind and its demand for the power. The BESS and the proposed algorithm appears to provide a balance in the energy between the hybrid convertor of the energy system as well as the demand for power and the load power dependent on wind speed and reduce power fluctuations. In this way, the power quality of the loads, in particular for systems without grid connection, is improved. In sudden changes the proposed system responds quickly to the transient and avoids the power oscillations.

\section{Conclusion}

In this study, a hybrid renewable energy system comprised of the energy obtained from wind including accumulator energy storage unit is designed and tested. It is concluded that the power quality problems caused by the variable factors in the wind turbine are reduced with the proposed system. The proposed system has reduced the fluctuations in power a better quality in power. At the same time, modeling has been found to improve system stability and reliability, and the proffered system takes a rapid transient response, providing a stability in the operation even under the unexpected circumstance. In this system, the energy supply and demand balance was realized and it was concluded that the efficiency of the system increased.

\section{References}

[1] Haan, J.E.S., Frunt J., Kling, W.L., 2010. Mitigation of wind power fluctuations in smart grids. In 2010 IEEE PES Innovative Smart Grid Technologies Conference Europe (ISGT Europe) (pp. 1-8). IEEE.

[2] Mathew, S., 2006. Wind energy, fundamentals, resource analysis and economics. Berlin, Germany, Springer.

[3] Heier, S., Waddington, R., 2006. Grid integration of wind energy conversion systems. 2nd ed. Hoboken, NJ, USA.

[4] Babazadeh, H., Gao, W., Wu, Z., and Li, Y., 2013. Optimal energy management of wind power generation system in islanded microgrid system, North American Power Symposium (NAPS) (pp. 1-5) IEEE.

[5] Ribeiro, P. F., Johnson Mariesa, B. K., Crow, L., Arsoy, A., and Liu Y., 2001. Energy storage systems for advanced power applications, proceedings of the IEEE 89(12), pp.1744-1756.

[6] Vazquez, S., Lukic, S.M., Galvan, E., Franquelo, L.G., and Carrasco, J.M., 2010. Energy storage systems for transport and grid applications. Transactions on industrial electronics, 57(12), pp.3881-3895.

ISSN: 2582-3051 
Journal of Electrical Engineering and Automation (EEA) (2019)

Vol.01/ No. 02

Pages: $72-82$

https://www.irojournals.com/iroeea

DOI: https://doi.org/10.36548/jeea.2019.2.002

[7] Carrasco, J.M., Franquelo, L.G., Bialasiewicz, J.T., Galván, E., Portillo Guisado, R.C., Prats A.M., Leónand J.I., and Moreno-Alfonso, N., 2006. Power-electronic systems for the grid integration of renewable energy sources: a survey. IEEE transactions on industrial electronics, 53(4), pp.1002-1016.

[8] Jiang, Q., Gong, Y., and Wang, H., 2013. A battery energy storage system dual-layer control strategy for mitigating wind farm fluctuations. IEEE transactions on power systems, 28(3), pp. 3263-3273.

[9] Shinji, T., Sekine, T., Akisawa, A., Kashiwagi, T., Fujita, G., and Matsubara, M., 2008. Reduction of power fluctuation by distributed generation in micro grid. Electrical engineering in Japan, 163(2), pp.22-29.

[10] Deshmukh, M.K., and Deshmukh, S.S., 2008. Modeling of hybrid renewable energy systems. Renew sustain energy rev., 12(1), pp.235-249.

[11] Mousavi, S.M., Fathi, S.H. and Riahy, G.H., 2009. Energy management of wind/pv and battery hybrid system with consideration of memory effect in battery. Clean Electrical Power 2009 International Conference.

[12] Wang, W., Mao, C., Lu, J., and Wang, D., 2013. An energy storage system sizing method for wind power integration. Energies, 6(7), pp.3392-3404.

[13] Sandia National Laboratories, Aug. 2012, National Wind and Solar Energy Storage and Transmission Demonstration Project (V). [Online]. Available: http://www.energystorageexchange.org/projects/159.

[14] Quanyuan, J., Yuzhong, G., and Haijiao W., 2013. A Battery energy storage system dual-layer control strategy for mitigating wind farm fluctuations. IEEE transactions on power systems, 28(3), pp.3263-3273.

[15] Shajari, S., Key Pour, R. (2012). Reduction of energy storage system for smoothing hybrid wind-PV power fluctuation, Environment and Electrical Engineering (EEEIC) 11th International Conference, pp.115-117.

[16] Xiangjun, L. Dong, H., and Xiaokang, L., 2013. Battery energy storage station (BESS)-Based smoothing control of photovoltaic (PV) and wind power generation fluctuations. IEEE Trans. Sustainable energy, 4(2), pp.464-473.

[17] Jiang, Q., Wang, H., 2013. Two-time-scale coordination control for a battery energy storage system to mitigate wind power fluctuations. IEEE Trans. Energy convers, 28(1), pp.52-61.

[18] Jiang, Q., Gong, Y., and Wang, H., 2013. A battery energy storage system dual-layer control strategy for mitigating wind farm fluctuations. IEEE Trans. Power syst., 28(3), pp.3263-3273.

[19] Buddika, D., Abeywardana, W., Hredzak, B., and Agelidis, V.G., 2017. A fixed-frequency sliding mode controller for a boost-1nverter-based battery-supercapacitor hybrid energy storage system. IEEE transactions on power systems, 32(1), pp.667-680.

[20] Hennessy, T., Kuntz, M., 2005. The multiple benefits of integrating electricity storage with wind energy in Proc. IEEE Power Eng. Soc. General meeting, pp.1952-1954.

[21] Xtreme Power Company, Xtreme Power's Dynamic Power Resource Online at Kahuku Wind Online. [Online]. Available: http://www. xtremepower.com/downloads/pressreleases/ 
Journal of Electrical Engineering and Automation (EEA) (2019)

Vol.01/ No. 02

Pages: $72-82$

https://www.irojournals.com/iroeea

DOI: https://doi.org/10.36548/jeea.2019.2.002

[22] Li, J., Liang, L., Yang S. L., and Hui D., 2010. Study on energy storage system smoothing wind power flutuations. Power System Technology (POWERCON), International Conference, pp.1-4.

[23] Cardenas, R., Pena, R., Asher, G., and Clare, J., 2004. Power smoothing in wind generation systems using a sensorless vector controlled induction machine driving a flywheel. IEEE trans. energy convers., 19(1), pp.206-216.

[24] Muyeen, S. M., Takahashi, R., Murata, T., and Tamura, J., 2009. Integration of an energy capacitor system with a variable-speed wind generator. IEEE trans. energy convers. 24(3), pp.740-749.

[25] Kinjo, T. Senjyu, T. Urasaki N., and Fujita H., 2006. Output levelling of renewable energy by Electric double-layer capacitor applied for energy storage system. IEEE trans. energy convers., 21(1), pp.221-227.

[26] Li, X., Yu-Jin, S., and Soo-Bin H., 2007. Study on power quality control in multiple renewable energy hybrid micro grid system. in Proc. IEEE power tech., pp.2000-2005.

[27] Li, X. Song, Y.-J., and Han, S.-B., 2008. Frequency control in micro-grid power system combined with electrolyzer system and fuzzy PI controller. J. power sources, 180(1), pp.468-475.

[28] Baran, M.E., Teleke, S., Anderson, L., Huang, A.Q., Bhattacharya S., and Atcitty S. 2008. STATCOM with energy storage for smoothing intermittent wind farm power, in Proc. Power and Energy Soc. General Meeting-Conv. and Delivery of Elect. Energy in the 21st Century, pp.1-6.

[29] Abbey, C. Strunz, K., and Joós, G., 2009. A knowledge-based approach for control of two-level energy storage for wind energy systems. IEEE Trans. Energy convers., 24(2), pp.539-547.

[30] Li, X., Li, Y., Han, X. and Hui, D., 2011. Application of fuzzy wavelet transform to smooth wind/PV hybrid power system output with battery energy storage system. Energy procedia, 12, pp.994-1001.

[31] Li, X., 2012. Fuzzy adaptive Kalman filter for wind power output smoothing with battery energy storage system. IET renew. power cenerat. 6(5), pp.340-347. 